\title{
Writing the Discussion
}

\author{
Kun Hwang, MD, PhD
}

Department of Plastic Surgery and the Center for Advanced Medical Education by the BK21 Project, Inha University School of Medicine, Incheon, Korea

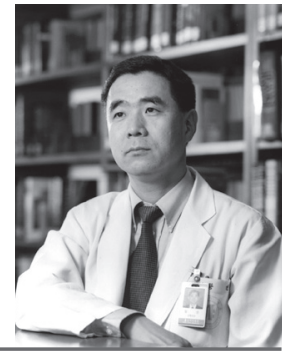

Some residents and junior staff members have asked me how to write the 'discussion part' of a scientific paper. In reviewing the manuscripts of original articles and case reports submitted to journals including the Archives of Plastic Surgery, I don't infrequently find or I frequently find that the authors have written summaries of references cited that are not directly related to the topic they are discussing. This paper is aimed at helping beginners easily start and end the discussion section of a journal article.

What do your findings mean? Why are they important? Discussion and conclusion sections exist to answer these questions [1]. Hess [2] summarized the tasks performed in the discussion as follows: state the study's major findings, explain the meaning and importance of the findings, relate the findings to those of similar studies, consider alternative explanations of the findings, state the clinical relevance of the findings, acknowledge the study's limitations, and make suggestions for further research. He also stated that elements to be avoided in the discussion are: over presentation of the results, unwarranted speculation, inflation of the importance of the findings, tangential issues, and the "bully pulpit" [2].

Most authors agree that beginning the discussion is difficult. Huth [3] emphasized that the opening of the discussion should give the answer to the research question. In the first paragraph of the section, state concisely the central conclusion, or answer, to be drawn from the data presented in the results.

In my experience, the easiest way to begin the discussion is to re-describe the purpose of the study and show that some (about $40 \%$ ) previous studies support or at least do not contradict my results. For example, "Results of this study 'correspond well with' those of an earlier study which...." Use phrases such as 'be quite similar to; resemble; in agreement with; almost identical to; coincide with; be in accord with; show similarity to' instead of repeating 'corresponds with' each time.

Then I present a lesser number (about 25\%) of previous stud- ies that contradict my results. An example is "Our findings are in contrast to the results of Hwang et al." Use the phrases 'differ from; be distinct from; do not correspond with; disagree with; be contrary to; be inconsistent with; be in disagreement with' as well.

The rest of the references (35\%) were already described in introduction and do not appear in the discussion again. Lastly, I indicate what is new (etwas neues in German) in my results and describe its significance. If you are sure of your findings, use 'prove'; in case you are less confident, use 'demonstrate, or document'. Usually 'show or indicate' is stronger than 'suggest, imply, suppose, or assume'. I usually do not repeat the same content or same contents that already appeared in the introduction.

The most important thing, I think, in writing the discussion is 'write the discussion for the reader' that is to say, be 'reader friendly'.

\section{REFERENCES}

1. Matthews JR, Bowen JM, Matthews RW. Successful scientific writing: a step-by-step guide for the biological and medical sciences. 2nd ed. Cambridge: Cambridge University Press; 2005.

2. Hess DR. How to write an effective discussion. Respir Care 2004;49:1238-41.

3. Huth EJ. How to write and publish papers in the medical sciences. 2nd ed. Philadelphia: Williams \& Wilkins; 1990.

Correspondence: Kun Hwang

Department of Plastic Surgery and the Center for Advanced Medical Education by the BK21 Project, Inha University School of Medicine, 27 Inhang-ro, Jung-gu, Incheon 400-711, Korea

Tel: +82-32-890-3514, Fax: +82-32-890-2918, E-mail: jokerhg@inha.ac.kr

No potential conflict of interest relevant to this article was reported.

Received: 22 Feb 2012 • Revised: 22 Feb 2012 • Accepted: 23 Feb 2012

pISSN: 2234-6163 • elSSN: 2234-6171

http://dx.doi.org/10.5999/aps.2012.39.3.183 • Arch Plast Surg 2012;39:183 